\title{
Porphyrin Core Dendrimers with Ether-Linked Carbazole Dendrons: Dual Luminescence of Core and Conformational Flexibility of Dendritic Shell
}

\author{
Nguyen Tran Nguyen, ${ }^{\mathrm{a}}$ Eduardo Coutico-Gonzalez, ${ }^{\mathrm{b}}$ Johan Hofkens, $^{\mathrm{b}}$ \\ Ivan G. Scheblykin, ${ }^{\mathrm{c}}$ Wim Dehaen, ${ }^{\mathrm{a}}$ and Mikalai Kruk ${ }^{\mathrm{d} @}$ \\ Dedicated to the Corresponding member of Russian Academy of Sciences Prof. Oscar Koifman \\ on the occasion of his $70^{\text {th }}$ Anniversary
}

\author{
${ }^{a}$ Molecular Design and Synthesis, Department of Chemistry, KU Leuven, Celestijnenlaan 200F, B-3001 Leuven, Belgium \\ ${ }^{\mathrm{b}}$ Molecular Imaging and Photonics, Department of Chemistry, KU Leuven, Celestijnenlaan 200F, B-3001 Leuven, Belgium \\ 'Lund University, Department of Chemical Physics, P.O. Box 124, 22100 Lund, Sweden \\ ${ }^{\mathrm{d} B e l a r u s i a n}$ State Technological University, Physics Department, 220006 Minsk, Belarus \\ ${ }^{\circledR}$ Corresponding author E-mail: krukmikalai@yahoo.com
}

\begin{abstract}
The ground state absorption spectra, spectra and lifetimes of the luminescence originating from the lowest $S_{1}(Q(0,0))$ and higher $S_{2}(B)$ excited states of porphyrin core in the dendrimers with ether-linked carbazole dendrons have been studied in detail. The relationship between the molecular design of the dendritic shell and the optical features of the dendrimer core in solution is presented. The influence of the axial ligation of the porphyrin core and the conformational flexibility of the dendritic shell on the luminescent properties of the studied dendrimers is revealed.
\end{abstract}

Keywords: Porphyrins, dendrimers, dendrons, luminescence, conformational flexibility.

\section{Аендримеры с порфириновым ядром и связанными эфирными мостиками карбазольными дендронами: Ауальная люминесценция яАра и конформационная подвижность АенАримерной оболочки}

\author{
Н. Т. Нгуен, ${ }^{a}$ Э. Коутиньо-Гонзалес, ${ }^{b}$ И. Хофркенс, ${ }^{\text {b }}$ И. Г. Щеблыкин, ${ }^{c}$ В. Аехаен, ${ }^{a}$ \\ H. Kpyк ${ }^{\mathrm{d}}$
}

Посвящается член-корреспонденту РАН профессору Оскару Иосифовичу Койфману по случаю его 70-летия

\footnotetext{
а Кафедра молекулярного дизайна и синтеза, Химический факультет, Католический университет Лёвена, Целестинианлаан 200Ф, В-3001 Лёвен, Бельгия

${ }^{\mathrm{b}}$ Кафедра молекулярной визуализации и фотоники, Химический факультет, Католический университет Лёвена, Целестинианлаан 200Ф, В-3001 Лёвен, Бельгия

'Университет Лунда, Кафедра химической физики, n/я 124, 22100 Лунд, Швеция

${ }^{\mathrm{d}}$ Белорусский государственньй технологический университет, кафедра физики, 220006 Минск, Беларусь

${ }^{@}$ E-mail:krukmikalai@yahoo.com
}

Детально изучены спектры поглощуения, спектры и времена жизни флуоресценции из нижнего синглетного $S_{1}(Q(0,0))$ и верхнего $S_{2}(B)$ возбужденных состояний порфириновго ядра в дендримерах с карбазольными дендронами, присоединенными к ядру посредством эфирных мостиков. Показана взаимосвязь молекулярной 
архитектуры дендримерной оболочки и оптических свойств дендримерного ядра. Обнаружено влияние аксиального лигандирования порфиринового ядра и конформаџионной подвижности дендримерной оболочки на люминесиентные свойства изученных дендримеров.

Ключевые слова: Порфирины, дендримеры, дендроны, люминесценция, конформационная подвижность.

\section{Introduction}

In recent years, much effort has been made to develop artificial devices mimicking the recognition processes occurring in nature. ${ }^{[1-8]}$ These applications often require a high sensitivity and discrimination capability, fast response and high stability. The architecture of the dendritic scaffold may serve as a useful tool for the tuning the optical properties and reactivity of the dendrimer core. [1] The dendritic encapsulation of tetrapyrrolic compounds with formation of dendrimers is of particular interest for their numerous applications exploiting the different properties of tetrapyrrolic compounds. ${ }^{[1,9]}$ The dendrimer core properties are expected to be greatly modified (enhanced or suppressed) with the control of the molecular conformation of the dendritic shell. This diversity gives the basis for the different spatial arrangement of functionalities and adjusting of macromolecular properties through the interplay of structural subunits. The morphology of the dendritic shell can vary significantly by using different dendrons and spacers. The diffusion rate of the specific guests in the bulk of the dendritic shell should depend strongly on the conformational flexibility of the dendritic shell. Thus, the core accessibility for both solvent molecules and specific guests (luminescence quenchers and ligating substances) can vary for several orders. ${ }^{[10]}$ This phenomenon can be treated in terms of both a "useful" shielding and an "injurious" effect which is slowing down the recognition interaction.

The excitation energy deactivation pathways in the tetrapyrrolic compounds are known to depend on the nature of the tetrapyrrolic ligand and the state of the macrocycle nucleus (being as the free base, chelated with metal ion, protonated or deprotonated) and the intermolecular interactions. Dendritic encapsulation with formation of dendrimers is able to bring significant perturbations in the photophysical properties of the tetrapyrrolic core. The electronic communication with dendron-substituents upon formation of the dendritic shell, steric restrictions on the conformational flexibility of macrocycle, local changes in the viscosity and polarity as well accessibility for molecular oxygen will substantially affect the photophysical and spectral properties of the tetrapyrrolic core.

Carbazole dendrons are considered as promising building blocks to prepare new functional dendrimers with a porphyrin core. ${ }^{[11-17]}$ Recently, we have reported on the synthesis of a series of new dendrimers with porphyrin core and carbazole dendrons differing in the spacer type used, ${ }^{[18-20]}$ and demonstrated the possibility to modulate the reactivity toward axial ligation and optical properties of porphyrin core by playing with the dendritic shell architecture.

In this paper, we present detailed studies of the luminescent features of the porphyrin dendrimers with ether- linked carbazole dendrons and report on the efficient control of the luminescent output of the dendritic shell by the solvent viscosity which affects its molecular conformation.

\section{Experimental}

\section{Studied Compounds}

The synthetic procedures applied to prepare and purify the compounds studied have been reported in detail recently. ${ }^{[20]}$ The molecular structure of the dendrimers studied and their abbreviations are shown in Scheme 1. The free base 5,10,15,20-tetraphenyl porphyrin TPP, 5,10,15,20-tetramesitylporphyrin $\mathbf{T M e s} \mathbf{P}$ and their $\mathrm{Zn}$ complexes $\mathbf{Z n T P P}$ and $\mathbf{Z n T M e s} \mathbf{P}$ have been used for reference purposes as the parent molecules (Scheme 2).

\section{Spectroscopic Methods and Instrumentation}

UV-vis spectra were taken on a Perkin-Elmer Lambda 20 or Cary Varian spectrophotometer. The fluorescence spectra and fluorescence excitation spectra have been measured using a SFL1211 spectrofluorometer (JSC Solar). The fluorescence decay kinetics have been measured using a home-made single photon counting spectrometer (KU Leuven). An OPA pumped modelocked Ti:sapphire laser (Tsunami, Spectra Physics) was used as the excitation source. Vertically oriented linearly polarized excitation light was prepared using a Berek compensator (New Focus) in combination with a polarization filter. The emission was collected under $90^{\circ}$ with respect to the incident light direction and guided through a polarization filter that was set at the magic angle $\left(54.7^{\circ}\right)$ with respect to the polarization of the excitation beam. The fluorescence was spectrally resolved by a monochromator (Sciencetech 9030, $6 \mathrm{~mm}$ bandwidth), and detected by a microchannel plate photomultiplier tube (MCP-PMT, R3809U, Hamamatsu). A time-correlated Single Photon Timing PC module (SPC 830, Becker \& Hickl) was used to obtain the fluorescence decay histogram in 4096 channels. The decays were recorded with 10,000 counts in the peak channel, in time windows of 25 ns corresponding to $6.1 \mathrm{ps} / \mathrm{channel}$ and analyzed globally with a time-resolved fluorescence analysis (TRFA) software. The full width at half-maximum (FWHM) of the IRF was typically in the order of 32 ps. The quality of the fits was judged by the fit parameters $\chi^{2}(<1.2), Z \chi^{2}(<3)$ and the Durbin Watson parameter $(1.8<\mathrm{DW}<2.2)$ as well as by the visual inspection of the residuals and autocorrelation function.

The absorbance and fluorescence measurements have been done in standard rectangular cells $(1 \times 1 \mathrm{~cm}$, Hellma) in air equilibrated solutions at $293 \pm 2 \mathrm{~K}$. The deoxygenated solutions have been used for the measurements of the fluorescence quantum yield and lifetime. Deoxygenation of the solutions has been performed by argon bubbling during 20 min just before measurements. The fluorescence quantum yield $\Phi_{\mathrm{fl}}$ has been determined using the standard sample method, with the Zn-5,10,15,20-tetraphenylporphyrin (Zn-TPP) or free base 5,10,15,20-tetraphenylporphyrin (TPP) in toluene taken as the standard samples $\left(\Phi_{\mathrm{fl}}^{0}=0.033\right.$ and 0.09 , respectively). 


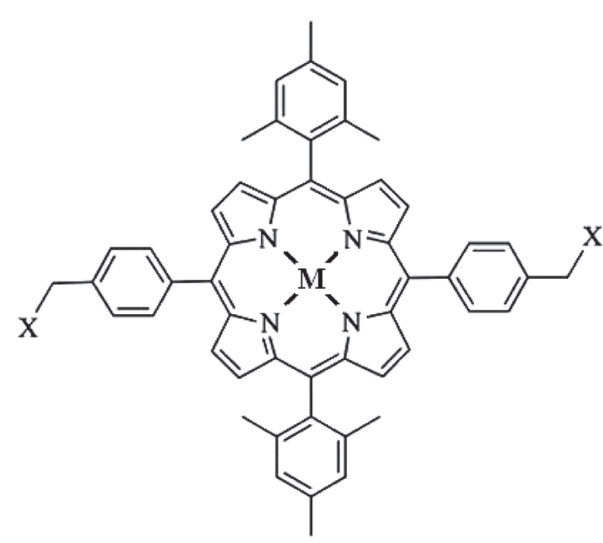

$\mathbf{M}=\mathbf{Z n} \quad \mathrm{ZnG}$

$\mathbf{M}=\mathbf{2 H} \quad \mathbf{G}$

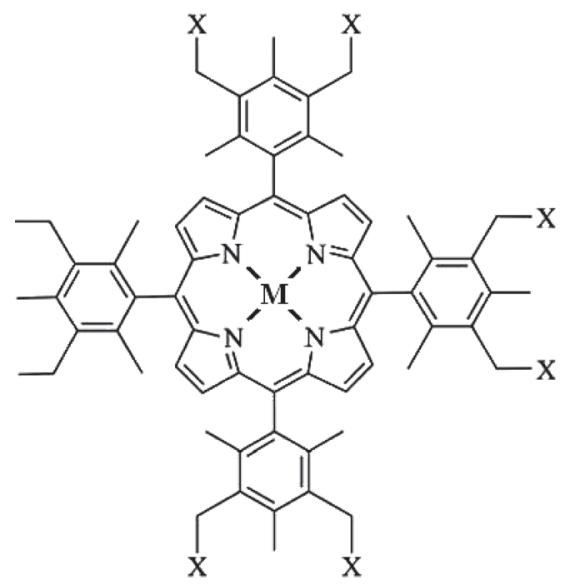

$\mathbf{M}=\mathbf{Z n} \quad \mathbf{Z n I}$

$\mathbf{M}=\mathbf{2 H} \quad$ I

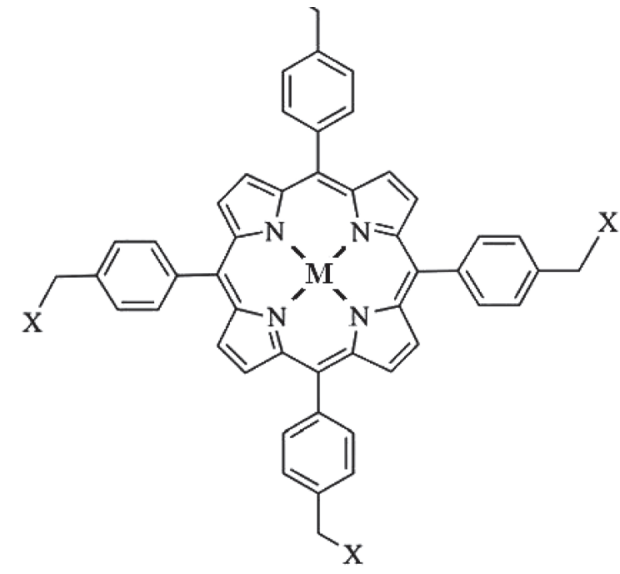

$\mathbf{M}=\mathbf{Z n} \quad \mathrm{ZnH}$

$\mathbf{M}=\mathbf{2 H} \quad \mathbf{H}$

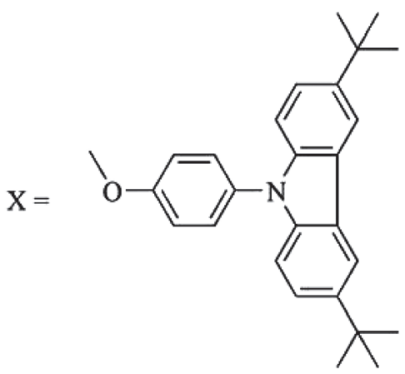

Scheme 1.
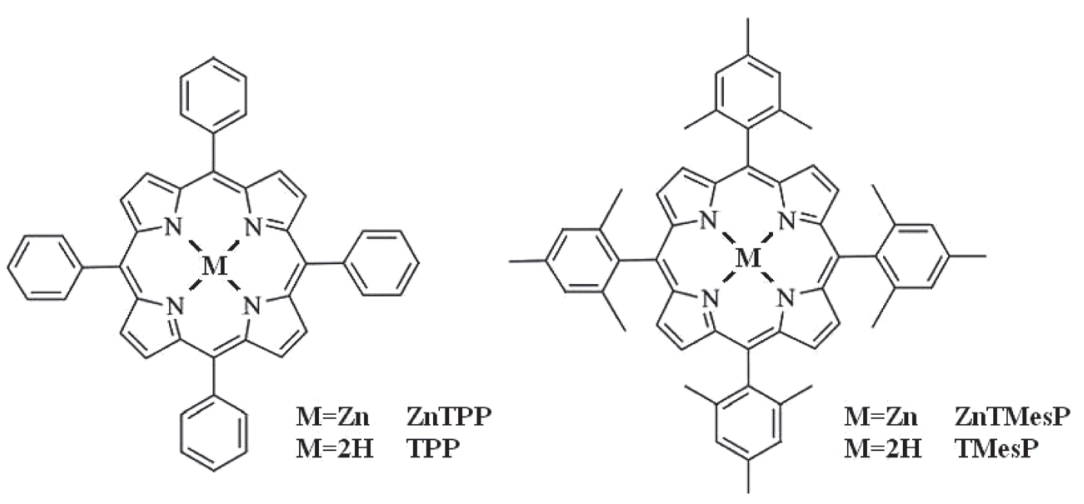

Scheme 2.

\section{Results and Discussion}

Absorption Spectra

Ground state absorption spectra of the studied dendrimers bear the features of both the porphyrin core and the carbazole dendrons. The ground state interaction of the

porphyrin core and the carbazole dendrons seems to be rather weak and both the core and dendritic shell chromophores retain their individual properties within the dendrimers. Thus, the carbazole absorbance brings unique characteristics to the dendrimer absorption spectra in the ultraviolet range, whereas the well-defined porphyrin core bands give rise to the absorbance in the near-UV and visible ranges (Soret 
and Q-bands, respectively). Therefore, it seems to be reasonable presenting these spectral features in consecutive order and then discussing the interchromophore shell-core interactions.

The state of the porphyrin core in the dendrimers under consideration can be varied due to the intrinsic features of the free base porphyrins consisting in the possibility to chelate the metal ions and to attach the external ligand when being chelated. ${ }^{[21]}$ As a result, we have prepared and studied the optical properties of three sets of dendrimers: a) the G-I dendrimers with the free base form of porphyrin core; b) the $\mathbf{Z n G - Z n I ~ d e n d r i m e r s ~ w i t h ~ t h e ~ f o u r - c o o r d i n a t e d ~}$ form of Zn-porphyrin core; c) the ZnG-THF - ZnI-THF dendrimers with the five-coordinated form of $\mathrm{Zn}$-porphyrin core ligated with THF. The spectral-luminescent data for the porphyrin core in these three sets of dendrimers are presented in Tables 1-3, respectively. The data presented in these tables indicate that the main difference in the visible range absorbance between the free base and the $\mathrm{Zn}$-porphyrin core consists in the number of bands. The two-fold increase in the molecular symmetry from $\mathrm{D}_{2 \mathrm{~h}}$ to $\mathrm{D}_{4 \mathrm{~h}}$ in going from the free base to the metallocomplexes is known to result in molecular orbital degeneration which leads to the apparent simplification of the spectrum. [21] However, the trends observed in all the three sets of spectra upon dendrimer formation are essentially the same, indicating that there are no noticeable differences in the interactions between the dendritic shell and the porphyrin core macrocycle. Recently, we have reported on the additive effect of dendron/substituent influence on the optical properties of the porphyrin core dendrimers with a different architecture of the dendritic shell. ${ }^{[22,23]}$ The spectral signature of the meso-aryl spacer rotational degree of freedom in the dendrimers with meso-aryl porphyrin core has been also reported..$^{[19,23]}$ We have found that bulky $\mathrm{CH}_{3}$-groups in the ortho-positions of the phenyl rings of "TMesP-like" dendrimers force the aryl rings to keep their planes in the perpendicular orientation with respect to the macrocycle mean plane, whereas protons in the orthopositions of the phenyl rings of "TPP-like" dendrimers do not, and the dihedral angle between these planes can be easily varied. We will now apply the same approach to the analysis of the visible range absorption spectra of the new dendrimers. The comparison should be made with the parent porphyrin molecules, which are also listed in the bottom rows in Tables 1-3. Thus, for example, in the case of the free base molecules the TPP is the parent porphyrin for the $\mathbf{H}$ dendrimer due to four freely rotating phenyl mesospacers and the TMesP with its four sterically hindered mesityl meso-spacers is the parent compound for the I dendrimer. The $\mathbf{G}$ dendrimer is of mixed trans $-\mathrm{Ph}_{2} \mathrm{Mes}_{2}$ architecture and should be considered as an intermediate between $\mathbf{H}$ and $\mathbf{I}$ dendrimers.

Formation of dendrimers leads to small long wavelength shifts for the absorption bands compared to parent porphyrins. These shifts in the absorption spectra parallel with the changes in the ratio $A_{0,0} / A_{1,0}$ of the intensities of pure electronic to vibronic bands (the same trend is valid in all the cases for the ratio $F_{0,0} / F_{0,1}$ of the bands in the fluorescence spectra). ${ }^{[24]}$ The $A_{0,0}{ }^{\prime} A_{1,0}$ value gives the ratio of the transition dipole moments of these transitions and is proportional to the square of the energy difference between the two one-electron configurations: $A_{0,0} / A_{1,0}$ $\sim\left[{ }^{1} E\left(a_{2 u}, e_{g)}-{ }^{1} E\left(a_{1 u}, e_{g}\right)\right]^{2}\right.$, and is used as a measure of the energy mismatch between the highest occupied molecular orbitals (HOMOs) $a_{2 u}$ and $a_{1 u}\left(\mathrm{D}_{4 \mathrm{~h}}\right.$ symmetry notation). ${ }^{[21]}$ Different $A_{0,0} / A_{1,0}$ ratio for the parent porphyrins (0.51 and 0.36 for the TPP and TMesP, respectively) reflects different electronic density redistribution between the tetrapyrrolic macrocycle and meso-aryl groups. An increase in the $A_{0,0} /$ $A_{1,0}$ ratio in case of the TPP relative to the TMesP is due to more electron density transferring to the macrocycle, which leads to an increase in the electron density at the mesocarbons of the porphyrin thus increasing the energy of the $a_{2 u}$ MO. The more separated in energy the $a_{2 u}$ and $a_{1 u}$ orbitals are, the higher the absorption of the 0,0 transition is. ${ }^{[25]}$ This trend keeps in all the dendrimers (Figure 1). The $A_{0,0} / A_{1,0}$ ratio decreases when going from "TPP-like" dendrimers to "TMesP-like" dendrimers independently the form of the dendrimer core. This observation indicates that the formation of the dendritic shell does not bring noticeable restrictions to the porphyrin core conformation in the ground electronic state. At the same time, one can see that the $A_{0,0} / A_{1,0}$ ratio is always higher in the dendrimers compared to that in parent porphyrins, indicating that the dendrons can be considered as slightly stronger electron donors.

The conformational flexibility/degree of freedom of the tetrapyrrolic macrocycle can be estimated with the Stokes shift $\Delta \lambda_{\text {Stokes }}=\lambda_{0,0}{ }^{\text {abs }}-\lambda_{0,0}{ }^{\text {fl }} \cdot{ }^{[26-30]}$ Based on the $\Delta \lambda_{\text {Stokes }}$ value behavior in dendrimers, one can estimate the influence of the dendritic shell on the intrinsic conformational flexibility of the porphyrin core. The smallest $\Delta \lambda_{\text {Stokes }}$ values have been determined for the dendrimers with the free base porphyrin core. Comparison of $\Delta \lambda_{\text {Stokes }}$ values with those for the parent porphyrins indicates that there is no observable change within the experimental error limits (the accuracy for the $\Delta \lambda_{\text {Stokes }}$ value determination is $\pm 25 \mathrm{~cm}^{-1}$, corresponding to a total accuracy of $\pm 1 \mathrm{~nm}$ in the determination of the maxima of absorption and fluorescence spectra). Therefore we suggest that there is no dendrimer induced conformational hindrance

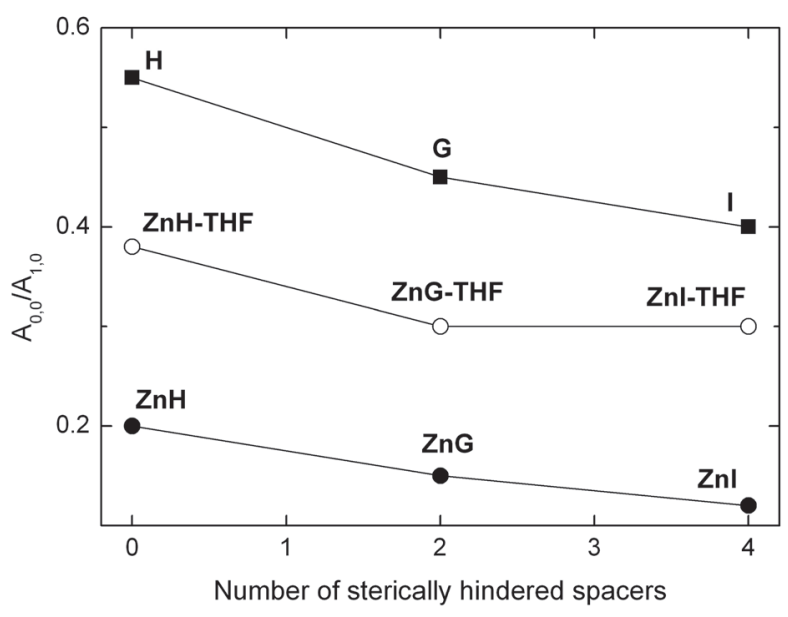

Figure 1. Correlation between $A_{0,0} / A_{1,0}$ ratio and the number of sterically hindered spacers in the studied compounds: the free base form of porphyrin core (closed squares), the four-coordinated form of $\mathrm{Zn}$-porphyrin core (closed circles), and the five-coordinated form of $\mathrm{Zn}$-porphyrin core (open circles). 
Table 1. Spectral-luminescent data for the studied compounds with the free base porphyrin core. Solvent is DCM.

\begin{tabular}{|c|c|c|c|c|c|c|c|c|c|}
\hline Compound & $\lambda_{\mathrm{x} 0,0}{ }^{\text {abs }}, \mathrm{nm}$ & $\lambda_{\mathrm{x} 1,0}{ }^{\text {abs }}, \mathrm{nm}$ & $\lambda_{\mathrm{y} 0,0}{ }^{\text {abs }}, \mathrm{nm}$ & $\lambda_{\mathrm{y} 1,0}$ abs, $\mathrm{nm}$ & $A_{0,0} / A_{1,0}$ & $\lambda_{0,0}{ }^{\mathrm{fl}}, \mathrm{nm}$ & $\lambda_{0,1}{ }^{\mathrm{fl}}, \mathrm{nm}$ & $F_{0,0} / F_{0,1}$ & $\Delta \lambda_{\text {Stokes }}, \mathrm{cm}^{-1}$ \\
\hline G & 646.0 & 591.0 & 549.5 & 514.5 & 0.45 & 649.0 & 715.5 & 1.45 & 72 \\
\hline H & 646.0 & 548.0 & 550.5 & 515.0 & 0.55 & 650.0 & 715.7 & 1.63 & 95 \\
\hline I & 649.0 & 592.0 & 549.0 & 516.0 & 0.40 & 650.0 & 719.0 & 1.25 & 23 \\
\hline TPP & 645.5 & 589.5 & 549.0 & 514.0 & 0.51 & 650.0 & 715.0 & 1.76 & 107 \\
\hline TMesP & 646.0 & 590.0 & 546.5 & 514.0 & 0.36 & 648.5 & 718.5 & 1.16 & 60 \\
\hline
\end{tabular}

Table 2. Spectral-luminescent data for the studied compounds with four-coordinated form of Zn-porphyrin core. Solvent is DCM.

\begin{tabular}{ccccccccc}
\hline Compound & $\lambda_{0,0}{ }^{\text {abs }}, \mathrm{nm}$ & $\lambda_{1,0}{ }^{\text {abs }}, \mathrm{nm}$ & $A_{0,0} / A_{1,0}$ & $\lambda_{0,0}{ }^{\mathrm{fl}}, \mathrm{nm}$ & $\lambda_{0,1}{ }^{\mathrm{fl}}, \mathrm{nm}$ & $F_{0,0} / F_{0,1}$ & $\Delta \lambda_{\text {Stokes }}, \mathrm{cm}^{-1}$ & $\Phi_{\mathrm{ff}} \times 10^{2}$ \\
\hline ZnG & 587.0 & 549.0 & 0.15 & 595.0 & 646.0 & 0.48 & 231 & 4.0 \\
ZnH & 586.5 & 548.0 & 0.20 & 597.0 & 646.5 & 0.61 & 300 & 4.0 \\
ZnI & 588.0 & 551.5 & 0.12 & 594.5 & 647.5 & 0.27 & 188 & 4.6 \\
ZnTPP & 585.5 & 547.5 & 0.17 & 595.0 & 645.0 & 0.48 & 272 & 3.3 \\
ZnTMesP & 586.0 & 549.0 & 0.09 & 594.0 & 646.5 & 0.24 & 230 & 3.2 \\
\hline
\end{tabular}

Table 3. Spectral-luminescent data for the studied compounds with five-coordinated form of Zn-porphyrin core. Solvent is THF.

\begin{tabular}{ccccccccc}
\hline Compound & $\lambda_{0,0}$ abs, $\mathrm{nm}$ & $\lambda_{1,0}$ abs, $\mathrm{nm}$ & $A_{0,0} / A_{1,0}$ & $\lambda_{0,0}{ }^{\mathrm{fl}}, \mathrm{nm}$ & $\lambda_{0,1}{ }^{\text {fl }}, \mathrm{nm}$ & $F_{0,0} / F_{0,1}$ & $\Delta \lambda_{\text {Stokes }}, \mathrm{cm}^{-1}$ & $\Phi_{\mathrm{ff}} \times 10^{2}$ \\
\hline ZnG-THF & 596.0 & 557.0 & 0.30 & 603.0 & 655.0 & 0.75 & 195 & 4.7 \\
ZnH-THF & 596.0 & 556.5 & 0.38 & 604.5 & 656.0 & 0.91 & 236 & 4.5 \\
ZnI-THF & 598.0 & 560.0 & 0.30 & 603.0 & 659.0 & 0.58 & 188 & 4.9 \\
ZnTPP-THF & 594.5 & 555.5 & 0.325 & 600.0 & 653.0 & 0.79 & 154 & 3.3 \\
ZnTMesP-THF & 595.5 & 558.5 & 0.260 & 598.0 & 654.0 & 0.51 & 71 & 3.6 \\
\hline
\end{tabular}

for the porphyrin core. In case of the four-coordinated $\mathrm{Zn}$ porphyrin core, the $\Delta \lambda_{\text {Stokes }}$ values are also of about the same magnitude as they are in the parent porphyrin for both TPPlike and TMesP-like dendrimers $\mathbf{Z n H}$ and $\mathbf{Z n I}$, and the Stokes shift value measured for the $\mathbf{Z n G}$ dendrimer is in line with this observation. A substantial decrease in the $\Delta \lambda_{\text {Stokes }}$ value takes place upon ligation of the parent porphyrins in THF (Tables 2 and 3). However, in the TPP-like dendrimer ZnH-THF the decrease in the $\Delta \lambda_{\text {Stokes }}$ value is found to be much smaller, and in the case of the TMesP-like dendrimer ZnI-THF it is exactly the same compared to those for the four-coordinated dendrimers $\mathbf{Z n H}$ and $\mathbf{Z n I}$. These differences can be considered as resulting from dendrimer induced conformational restrictions for the porphyrin core. They prevent the intrinsic conformational rearrangements need to occur in the excited $S_{1}$ state for axially ligated porphyrins after photoexcitation. This behavior is different from the one we have reported recently for the dendrimers with triazole linkage between carbazole dendrons and porphyrin core, ${ }^{[19]}$ where the same $\Delta \lambda_{\text {Stokes }}$ values were found for both parent Zn-porphyrins in THF solution and their dendrimer core counterparts. One can suggest that the dendritic shell with ether linkage has different conformational dynamics which seem to be solvent dependent. The study of this issue is expounded in a separate paragraph below.

\section{Luminescent Properties}

The lowest singlet $\mathrm{S}_{1}$ state of the free base G-I dendrimers is fluorescent (Figure 2), around 11\% of excited molecules deactivate through the $\mathrm{S}_{1} \rightarrow \mathrm{S}_{0}$ fluorescence (Table 4). Formation of dendrimers leads to a slight increase in both emission $k_{\mathrm{ff}}$ and radiationless deactivation $k_{\mathrm{nr}}$ rates, resulting in a moderate increase in the fluorescence quantum yield $\Phi_{\mathrm{ff}}$. The fluorescence quantum yield $\Phi_{\mathrm{fl}}$ decreases strongly in going from the free base to the Zn-porphyrin core dendrimers, in line with the trend observed for the parent porphyrins (see Tables 2, 3 and 4). ${ }^{[31]}$

Table 4. Luminescent properties for $S_{1}$ state of the studied compounds with the free base porphyrin core. Solvent is DCM.

\begin{tabular}{ccccc}
\hline Compound & $\Phi_{\mathrm{ff}} \times 10^{2}$ & $\tau_{\mathrm{ff}}, \mathrm{ns}$ & $k_{\mathrm{f}}, 10^{7} \mathrm{~s}^{-1}$ & $k_{\mathrm{nr},}, 10^{7} \mathrm{~s}^{-1}$ \\
\hline $\mathbf{G}$ & 10.7 & 9.2 & 1.16 & 9.71 \\
$\mathbf{H}$ & 11.3 & 8.2 & 1.39 & 10.8 \\
$\mathbf{I}$ & 10.9 & 9.2 & 1.19 & 9.68 \\
$\mathbf{T P P}$ & 9.0 & 12.2 & 0.74 & 8.10 \\
\hline
\end{tabular}

The TMesP-like dendrimers have the highest quantum yield $\Phi_{f l}$ value in both cases of the four and five-coordinated Zn-porphyrin core dendrimers. This is in contrast with the free base dendrimers where the TPP-like $\mathbf{H}$ dendrimer has the highest fluorescence quantum yield, as well as with the quantum yield data for the parent porphyrins in solution (see Tables 2, 3, and Ref. ${ }^{[32]}$ ). It is obvious that this specificity arises from different interactions between the dendritic shell and porphyrin macrocycle in the excited state, since the hindrance free meso-phenyl and hindered meso-mesityl groups provide different conditions for it, as was stressed 

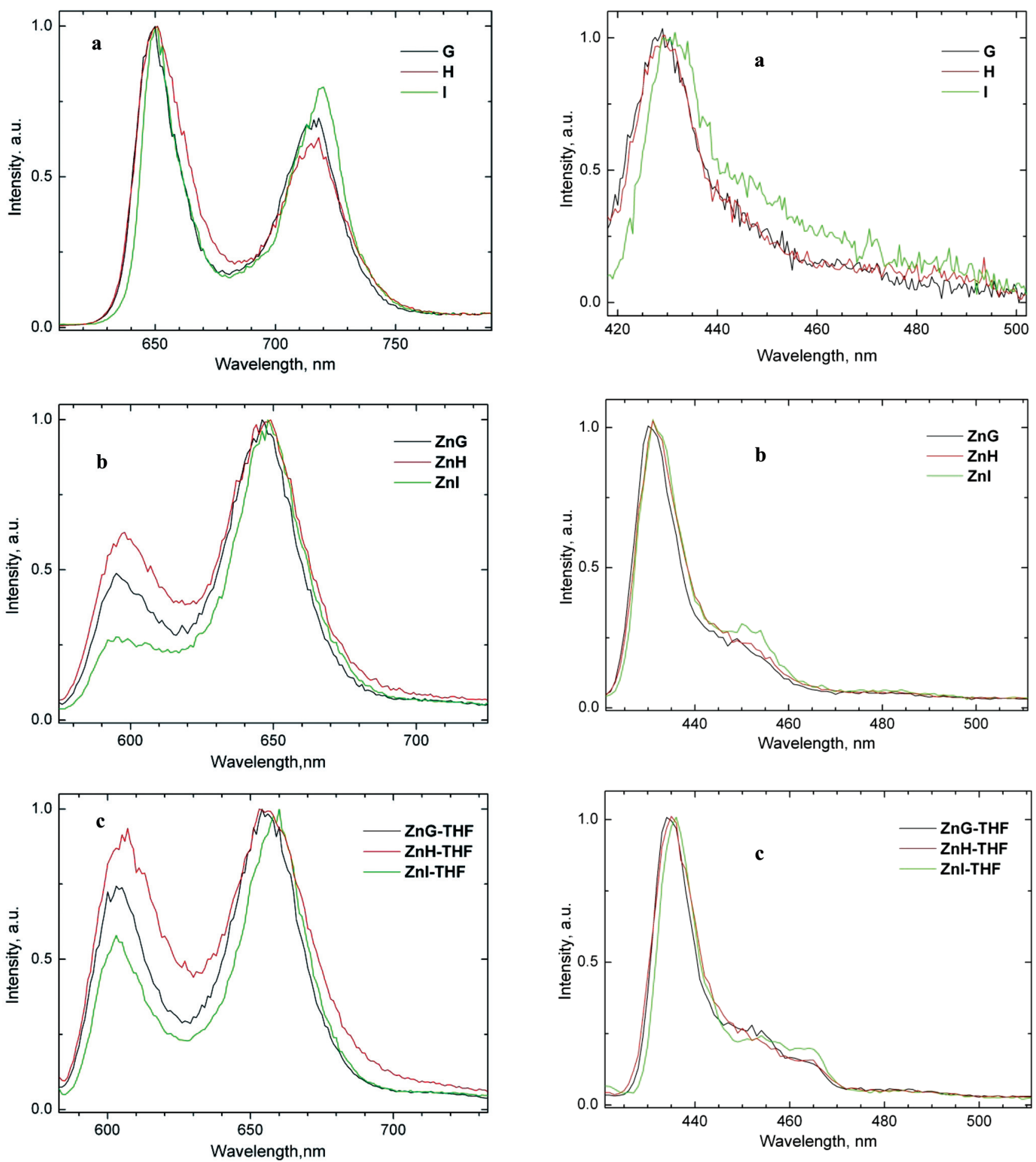

Figure 2. The $S_{1} \rightarrow S_{0}$ fluorescence spectra for the studied compounds: (a) free base porphyrin core $\mathbf{G}-\mathbf{I}$ dendrimers, $\lambda_{\text {exc }}=$ $550 \mathrm{~nm}$; (b) four-coordinated $\mathbf{Z n}$-porphyrin core $\mathbf{Z n G}-\mathbf{Z n I}$ dendrimers, $\lambda_{\text {exc }}=570 \mathrm{~nm}$; (c) five-coordinated Zn-porphyrin core $\mathbf{Z n G - T H F}-\mathbf{Z n I - T H F}$ dendrimers, $\lambda_{\text {exc }}=578 \mathrm{~nm}$. Spectra of the $\mathbf{G}-\mathbf{I}$ dendrimers are normalized for the intensity of the electronic $(0,0)$ band, spectra of the $\mathbf{Z n G}-\mathbf{Z n I}$ and $\mathbf{Z n G - T H F}$ - ZnI-THF dendrimers are normalized for the intensity of the vibronic $(0,1)$ band.

above when analyzing the Stokes shift behavior. Dendrimer $\mathbf{G}$ with mixed trans- $\mathrm{Ph}_{2} \mathrm{Mes}_{2}$ architecture provides the largest difference in the $\Phi_{\mathrm{fl}}$ value between the four- and fivecoordinated forms.

Figure 3. The $\mathrm{S}_{2} \rightarrow \mathrm{S}_{0}$ fluorescence spectra for the studied compounds: (a) free base porphyrin core $\mathbf{G}-\mathbf{I}$ dendrimers, $\lambda_{\text {exc }}$ $=405 \mathrm{~nm}$; (b) four-coordinated Zn-porphyrin core $\mathbf{Z n G}-\mathbf{Z n I}$ dendrimers, $\lambda_{\text {exc }}=395 \mathrm{~nm}$; (c) five-coordinated Zn-porphyrin core ZnG-THF - ZnI-THF dendrimers, $\lambda_{\text {exc }}=405 \mathrm{~nm}$. All the spectra are normalized to the maximum intensity of the electronic $(0,0)$ band.

Several tetrapyrrolic compounds are known to have dual fluorescence, i.e. they possess the fluorescence from the higher excited state in addition to the usual fluorescence from the lowest singlet $\mathrm{S}_{1}$ state. ${ }^{[33-39]}$ In most of the cases, this fluorescence is observed for the metallocomplexes and can be denoted therefore as $\mathrm{S}_{2} \rightarrow \mathrm{S}_{0}$ fluorescence (frequently 


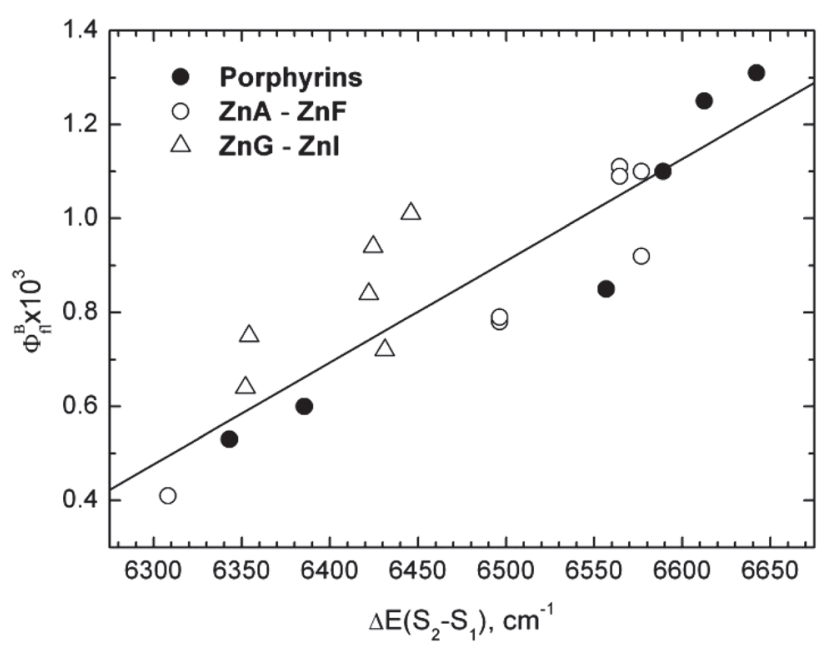

Figure 4. Correlation between blue $\mathrm{S}_{2} \rightarrow \mathrm{S}_{0}$ fluorescence quantum yield $\Phi_{\mathrm{fl}}{ }^{\mathrm{B}}$ and the energy gap $\Delta E\left(\mathrm{~S}_{2}-\mathrm{S}_{1}\right)$ for the compounds studied. The data set included in the plot taken partly a recent paper of our group. ${ }^{[19]}$

Table 5. Luminescent properties for the $\mathrm{S}_{2}$ state of all the studied compounds.

\begin{tabular}{cccc}
\hline Compound & $\lambda_{0,0}{ }^{\mathrm{fl}}, \mathrm{nm}$ & $\lambda_{0,1}{ }^{\mathrm{fl}}, \mathrm{nm}$ & $\Phi_{\mathrm{fl}}{ }^{\mathrm{B}} \times 10^{3}$ \\
\hline $\mathbf{G}$ & 429.0 & - & 0.021 \\
$\mathbf{H}$ & 429.5 & - & 0.022 \\
$\mathbf{I}$ & 431.5 & - & 0.017 \\
TPP & 429.5 & - & 0.014 \\
$\mathbf{Z n G}$ & 430.5 & - & 0.84 \\
$\mathbf{Z n H}$ & 431.5 & - & 0.94 \\
ZnI & 431.5 & 453.5 & 0.75 \\
ZnTPP & 427.0 & - & 1.25 \\
ZnTMesP & 427.5 & - & 0.85 \\
ZnG-THF & 434.5 & - & 0.78 \\
ZnH-THF & 435.0 & - & 1.09 \\
ZnI-THF & 436.0 & - & 0.71 \\
ZnTPP-THF & 430.0 & 454.0 & 1.10 \\
ZnTMesP-THF & 428.0 & 455.0 & 1.31 \\
\hline
\end{tabular}

also named as blue fluorescence due to the emission spectral range). The list of the free base tetrapyrrolic compounds having blue fluorescence is limited. ${ }^{[34,38,39]}$ The blue fluorescence quantum yield $\Phi_{\mathrm{fl}}{ }^{\mathrm{B}}$ is determined by the competition of the $\mathrm{S}_{2} \rightarrow \mathrm{S}_{0}$ emission deactivation rate and the $\mathrm{S}_{2} \rightarrow \mathrm{S}_{1}$ radiationless deactivation rate. It is expected that in the case of the free base molecules, the stretching $\mathrm{NH}$ modes have a huge impact to the increase in the $\mathrm{S}_{2} \rightarrow \mathrm{S}_{1}$ radiationless deactivation rate, so the $\mathrm{S}_{2} \rightarrow \mathrm{S}_{0}$ emission deactivation rate can not compete with it more. ${ }^{[35]}$

Our results demonstrate that the dendritic encapsulation is able to change the proportion of these two rates for the free base molecules, leading to a blue fluorescence emission of observable intensity. Thus, a barely distinguishable $\mathrm{S}_{2} \rightarrow \mathrm{S}_{0}$ fluorescence signal is measured for TPP, and the blue fluorescence quantum yield $\Phi_{\mathrm{fl}}{ }^{\mathrm{B}}$ is estimated as low as $1.4 \cdot 10^{-5}$. Formation of the dendrimer $\mathbf{H}$ leads to a noticeable increase in the $\Phi_{\mathrm{fl}}{ }^{\mathrm{B}}$ value up to $2.2 \cdot 10^{-5}$ (Table 5). The blue $\mathrm{S}_{2} \rightarrow \mathrm{S}_{0}$ fluorescence is also observed for two other studied dendrimers with the free base porphyrin core (Figure 3). Dendrimers having Zn-porphyrin core reveal the $\mathrm{S}_{2} \rightarrow \mathrm{S}_{0}$ fluorescence with a quantum yield $\Phi_{\mathrm{fl}}{ }^{\mathrm{B}}$ value being almost two orders of magnitude higher (Figure 3, Table 5). This demonstrates once again the importance of the tetrapyrrolic macrocycle state for the quantum yield of fluorescence from higher excited states. The trend in the quantum yield $\Phi_{\mathrm{fl}}{ }^{\mathrm{B}}$ value for all three series of dendrimers is the same, namely, the TPP-like dendrimers have the highest quantum yield, the dendrimers with mixed trans $-\mathrm{Ph}_{2} \mathrm{Mes}_{2}$ architecture reveal intermediate $\Phi_{\mathrm{fl}}{ }^{\mathrm{B}}$ values and the TMesP-like dendrimers have the lowest values. It is worthwhile to note that the four- and five coordinated porphyrin core dendrimers do not follow the trend in the $\Phi_{\mathrm{fl}}{ }^{\mathrm{B}}$ changes observed for the parent porphyrins in the solution. However, one can suggest that the energy gap $\Delta E\left(\mathrm{~S}_{2}-\mathrm{S}_{1}\right)$ is the main factor influencing the blue fluorescence quantum yield for all the dendrimers with $\mathrm{Zn}$ porphyrin core (see Figure 4, where the plot consists of also the dendrimer series with triazole linkers studied recently $\left.{ }^{[19]}\right)$. The radiationless internal conversion probability $k_{\mathrm{IC}}\left(\mathrm{S}_{2} \rightarrow \mathrm{S}_{1}\right)$ is known to be reciprocal to the $\Delta E\left(\mathrm{~S}_{2}-\mathrm{S}_{1}\right),{ }^{[35]}$ therefore a good linear correlation between the $\Phi_{\mathrm{fl}}^{\mathrm{B}}$ value and $\mathrm{S}_{2}-\mathrm{S}_{1}$ energy gap may be explained with changes in the $k_{\mathrm{IC}}\left(\mathrm{S}_{2} \rightarrow \mathrm{S}_{1}\right)$ due to variation of the energy gap $\Delta E\left(\mathrm{~S}_{2}-\mathrm{S}_{1}\right)$, whereas the emission probability $k_{\mathrm{fl}}\left(\mathrm{S}_{2} \rightarrow \mathrm{S}_{0}\right)$ remains about the same. The minor variation of the $k_{\mathrm{fl}}\left(\mathrm{S}_{2} \rightarrow \mathrm{S}_{0}\right)$ value seem to be responsible for some scattering in the analyzed data.

\section{Dendron Photophysics and Conformational Dynamics}

We have suggested above that the dendrimer I reveals solvent dependent conformational dynamics. This expectation is based on the substantial difference of the Stokes shift value between the dendrimer $\mathbf{I}$ and its parent TMesP in THF solution upon the formation of five-coordinated form, whereas no such difference is observed in the case of fourcoordinated compounds in DCM. Here we report on the photophysical properties of the carbazole dendrons (Scheme 3 ). The ground state interactions between the carbazole units within dendrons I can be estimated as very weak since there is no noticeable difference in the spectral profile between the dendron I, consisting of two carbazole units, dendron $\mathbf{G}(\mathbf{H})$, possessing only one carbazole unit, and the carbazole-phenol (CZ-Ph-OH) taken as the reference compound (Figure 5). The fluorescence spectra profiles have also the same positions of the maxima and fully coincide being intensity normalized. However, the fluorescence intensity differs strongly in these compounds (Figure 5). The minimal fluorescence intensity of $1 / 10$ of that for carbazole-phenol CZ-Ph-OH is measured for the dendrons $\mathbf{G}(\mathbf{H})$. It seems to be due to the large conformational flexibility of this structure, resulting in the enhancement of the radiationless deactivation of fluorescence $\mathrm{S}_{1}$ state of the carbazole unit. The conformational flexibility arises mainly from the high rotation degree of freedom at the ether bridge (see Scheme 3, red arrows). Such conformational flexibility of the ether bridge allow the bending and folding of the dendrons of $\mathbf{G}$ and $\mathbf{H}$, and the resulting conformers may possess an enhanced radiationless deactivation rate. ${ }^{[40]} \mathrm{A}$ threefold increase in the fluorescence intensity is observed for 


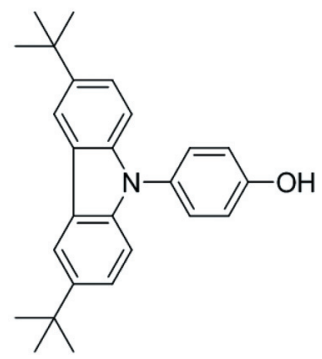

CZ-Ph-OH

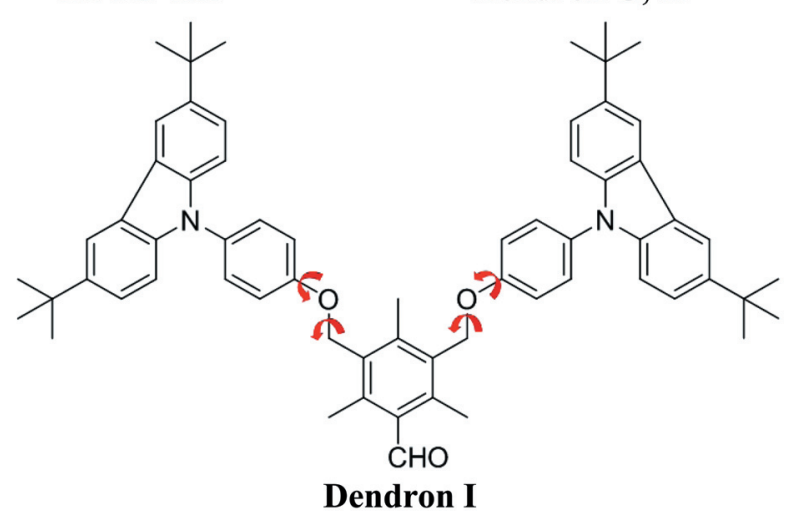

Scheme 3 .

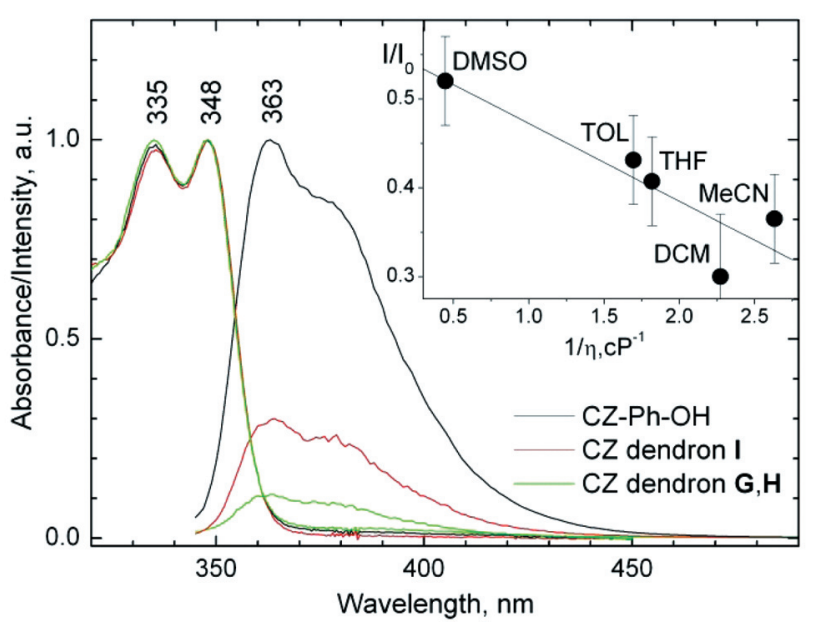

Figure 5. Absorption and fluorescence spectra of carbazole dendrons in DCM. Fluorescence spectra are absorbance normalized $\left(\lambda_{\text {exc }}=340 \mathrm{~nm}\right)$ and reduced to the integral intensity of $\mathrm{CZ}-\mathrm{Ph}-\mathrm{OH}$. Inset shows the relative fluorescence intensity

$I / I_{0}$ of the carbazole $\mathbf{I}$ dendron as a function of solvent fluidity. $I_{0}$ is fluorescence intensity of CZ-Ph-OH.

the dendrons I, where the substitution of two carbazole units into the meta-positions of mesityl ring leads to limitations of conformational mobility, which prevent adopting (some of) these strongly bent "nonfluorescent" conformation(s).

The fluorescence intensity of the carbazole I dendron depends on the solvent fluidity (Figure 5, inset). Increase in the viscosity (decrease in the fluidity) leads to an increase in the fluorescence intensity. This observation is in line with the hypothesis, suggested above, that the carbazole fluorescence quenching is solvent dependent and coupled with conformational changes. Higher viscosity is slowing down the conformational changes in the excited state and decreases the probability to achieve the "nonfluorescent" conformer. Thus, the solvent viscosity is a tool to control the conformational mobility of the dendrons and, as a result, to control the dendron fluorescence quantum yield. The studied dendrimers with ether linkage between the carbazole units and the tetra-aryl-porphyrin core reveal a completely different solvent behavior compared to that reported earlier by us for the porphyrin core dendrimers with another dendritic shell architecture. ${ }^{[11]}$ The small changes in the linkage between the units within dendrons seem to be a promising way to design molecules with desired optical properties.

\section{Conclusions}

The spectral luminescent properties of a family of dendrimers with porphyrin core and ether-linked carbazole dendrons have been studied. Both free-base and $\mathrm{Zn}$-porphyrin core dendrimers were shown to have dual fluorescence in the blue and red spectral ranges. The properties of the fluorescent $\mathrm{S}_{1}$ state of the porphyrin core in dendrimers has been studied in detail and it was shown that the observed data can be rationalized in terms of the type of meso-spacer between the macrocycle and the dendritic shell. The dendritic shell allows the porphyrin core to adopt a dome type conformation upon formation of a five-coordinated $\mathrm{Zn}$-porphyrin core species for all the studied dendrimers, but the structure of the dendrons cause individuality of the optical response of the porphyrin core. The blue $\mathrm{S}_{2} \rightarrow \mathrm{S}_{0}$ fluorescence has been characterized for all the compounds and it was shown that dendritic encapsulation leads to a decrease in the radiationless internal conversion probability $k_{\mathrm{IC}}\left(\mathrm{S}_{2} \rightarrow \mathrm{S}_{1}\right)$ in the dendrimers with the free base porphyrin core as compared to the parent free base porphyrins in solution. The energy gap law for the $k_{\mathrm{IC}}\left(\mathrm{S}_{2} \rightarrow \mathrm{S}_{1}\right)$ probability has been confirmed using a large set of $\mathrm{Zn}$-porphyrin core dendrimers having the meso-aryl spacers with different rotational degree of freedom. The fluorescence quantum yield depends strongly on the structure and molecular conformation of the dendrons and was shown to be in tune with the solvent viscosity.

Acknowledgements. This work was supported by a FP-7 grant from the EC for Research, Technological Development and Demonstration Activities, "Dendrimers for Photonic Devices" IRSES-PEOPLE-2009-247260-DphotoD, under the "International Research Staff Exchange Scheme". W. Dehaen, J. Hofkens and E. Coutiño-Gonzalez also thank the FWO (Fund for Scientific Research - Flanders), the $\mathrm{KU}$ Leuven and the Ministerie voor Wetenschapsbeleid for continuing financial support. The Belgian co-authors acknowledge BELSPO for the frame of the IAPP7/05 network, facilitating their collaboration. Nguyen Tran Nguyen thanks Ministry of Education and Training, Vietnam International Education Development (VIED) for financial support during his $\mathrm{PhD}$ in KU Leuven, Belgium. Mikalai Kruk has been also supported by the State Program of Scientific Researches of the Republic of Belarus "Convergence", project 3.2.02 "Synthesis of new tetrapyrroles containing supramolecular systems and their applications for the luminescent sensors design". 


\section{References}

1. Hecht S., Frechet J.M.J. Angew. Chem., Int. Ed. Engl. 2001, 40, 74-91.

2. Li W.-S., Jiang D.-L., Suna Y., Aida T. J. Am. Chem. Soc. 2005, 127, 7700-7702.

3. Bosman A.W., Janssen H.M., Meijer E.W. Chem. Rev. 1999, 99, 1665-1674.

4. Gorman C.B., Smith J.C. Acc. Chem. Res. 2001, 34, 60-71.

5. Jiang D.-L., Aida T. J. Am. Chem. Soc. 1998, 120, 1089510901.

6. Finikova O., Galkin A., Rozhkov V., Cordero M., Hagerhall C., Vinogradov S. J. Am. Chem. Soc. 2003, 125, 4882-4892.

7. Finikova O.S., Troxler Th., Senes A., De Grado W.F., Hochstrasser R.M., Vinogradov S.A. J. Phys. Chem. A 2007, 111, 6977-6987.

8. Albrecht K., Kasai Y., Kuramoto Y., Yamamoto K. Chem. Commun. 2013, 49, 865-867.

9. Maes W., Dehaen W. Eur. J. Org. Chem. 2009, 4719-4752.

10. Collman J.P., Fu L., Zingg A., Diederich F. Chem. Commun. 1997, 193-197.

11. Loiseau F., Campagna S., Hameurlaine A., Dehaen W. J. Am. Chem. Soc. 2005, 127, 11352-11363.

12. Xu T.H., Lu R., Qiu X.P., Liu X.L., Xue P.C., Tan C.H., Bao C.Y., Zhao Y.Y. Eur. J. Org. Chem. 2006, 17, 4014-4020.

13. Li Y., Rizzo A., Salerno M., Mazzeo M. Appl. Phys. Lett. 2006, 89, 061125/1-061125/3.

14. Xu T., Lu R., Liu X., Zheng X., Qiu X., Zhao Y. Org. Lett. 2007, 9, 797-800.

15. Albrecht K., Kasai Y., Kimoto A., Yamamoto K. Macromolecules 2008, 41, 3793-3800.

16. Albrecht K., Kasai Y., Kimoto A., Yamamoto K. Chem. Commun. 2013, 49, 6861-6863.

17. Albrecht K., Kasai Y., Kimoto A., Yamamoto K. Chem. Commun. 2013, 49, 865-867.

18. Nguyen N.T., Mamardashvili G., Gruzdev M., Mamardashvili N., Dehaen W. Supramol. Chem. 2013, 25, 180-188.

19. Nguyen N.T., Hofkens J., Scheblykin I., Kruk M., Dehaen W. Eur. J. Org. Chem. 2014, 1766-1777.

20. Nguyen N.T., Mamardashvili G.M., Kulikova O.M., Scheblykin I.G., Mamardashvili N.Zh., Dehaen W. RSC $A d v$. 2014, 4, 19703-19709.
21. Gouterman M. Optical Spectra and Electronic Structure of Porphyrins and Related Rings. In: The Porphyrins, Vol. 3 (Dolphin D., Ed.), N.Y., 1978, p. 1-165.

22. Maes W., Ngo Th.H., Rong Gu, Starukhin A.S., Kruk M.M., Dehaen W. Eur. J. Org. Chem. 2010, 2576-2586.

23. Kruk M., Starukhin A., Maes W., Ngo T., Dehaen W., Proceedings of X-th International Conference on "Molecular, Membrane and Cell Basis of Biological Systems Functioning". Vol. 2, Minsk, 2012, 92-94.

24. For the free base compounds $A_{0,0} / A_{1,0}=\left(A_{\mathrm{x} 0,0}+A_{\mathrm{y} 0,0}\right) /\left(A_{\mathrm{x} 1.0}+A_{\mathrm{y} 1,0}\right)$ according to: Spellane P.J., Gouterman M., Antipas A., Kim S., Liu Y.C. Inorg. Chem. 1980, 19, 386-391.

25. Meot-Ner M., Adler A.D. J. Am. Chem. Soc. 1975, 94, 51075111.

26. Senge M.O. J. Photochem. Photobiol. B: Biol. 1992, 16, 3-36.

27. Shelnutt J.A., Song X.-Z., Ma J.-G., Jia S.-L., Jentzen W., Medforth C.J. Chem. Soc. Rev. 1998, 27, 31-41.

28. Knyukshto V.N., Solovyov K.N., Egorova G.D. Biospectrosc. 1998, 4, 121-133.

29. Senge M.O. Chem. Commun. 2006, 2, 243-256.

30. Röder B., Büchner M., Rükman I., Senge M.O. Photochem. Photobiol. Sci. 2010, 9, 1152-1158.

31. Quimby D.J., Longo F.R. J. Am. Chem. Soc. 1975, 94, 51075112.

32. Kruk M.M., Starukhin A.S., Maes W. Macroheterocycles 2011 4, 69-79.

33. Bajema L., Gouterman M., Rose C.B. J. Mol. Spectr. 1971, 39, 421-431.

34. Zalesskii E., Kotlo V.N., Solovyov K.N. Doklady Physics 1973, 210, 312-315 (in Russ.).

35. Kurabayashi Y., Kikuchi K., Kokubun H., Kaizu Y., Kobayashi H. J. Phys. Chem. 1984, 88, 1308-1310.

36. Aaviksoo J., Freiberg A., Savikhin S. Chem. Phys. Lett. 1984, $111,275-278$

37. Ohno O., Kaizu Y., Kobayashi H. J. Chem. Phys. 1985, 82, 1779-1787.

38. Arabei S.M., Egorova G.D., Solovev K.N., Shkirman S.F. Opt. Spectrosc. 1985, 59, 296-298.

39. Akimoto S., Yamazaki T., Yamazaki I., Osuka A. Chem. Phys. Lett. 1999, 309, 177-182.

40. Lakowicz J.R. Principles of Fluorescence Spectroscopy, $3^{\text {rd }}$ ed., Springer Science+Business Media, LLC, NY, 2006. 954 p.

Received 15.07.2014

Accepted 22.09.2014 